\title{
Psychiatric problems and its contributing factors in children and adolescents with hemophilia: a single centre study in a Turkish sample
}

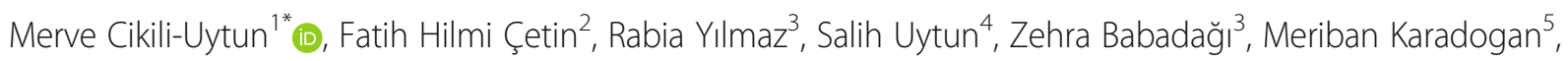
Fatma Turkan Mutlu ${ }^{5}$ and Yasemin Altuner-Torun ${ }^{5}$

\begin{abstract}
Background: We aimed to evaluate the psychiatric symptoms in addition quality of life in children and adolescents with hemophilia and to determine which factors contributed to psychiatric problems of them.

A total of 20 children and adolescents with hemophilia A or B and 20 healthy controls, aged 6-16years old, were included. Kiddie-Schedule for Affective Disorders and Schizophrenia, present and life time version (K-SADS-PL) was applied to parents. Sociodemographic questionnaire, Child Depression Inventory (CDI), The Spielberger State-Trait Anxiety Inventory (STAI), and KINDL ${ }^{R}$ Questionnaire was used for children and adolescents in both groups. Beck Depression Inventory (BDI), Beck Anxiety Inventory (BAI), and KINDL parent form were used for mothers in both groups.

Results: The study results demonstrated higher anxiety scores and increased anxiety disorder diagnosis among children and adolescents with hemophilia. However, mother's anxiety and depression scores are higher than control group, and QoL of their children also shows lower scores in parents' KINDL forms. Mothers' depression and anxiety scores are associated with childrens' depression, anxiety, and QoL scores.
\end{abstract}

Conclusion: Psychiatric factors should not be ignored in the treatment and follow-up of children and adolescents with hemophilia and their parents.

Keywords: Children, Hemophilia, Mothers, Psychiatry

\section{Background}

Hemophilia is the most common of the severe bleeding disorders and can be treated most efficaciously and safely among the most prevalent monogenic disorders, but if not diagnosed and treated on early infancy, it can lead to chronic disease and disabilities [1].

The quality of life (QoL) of children with chronic conditions has received increasing attention in recent years especially for frequent pediatric diseases such as asthma,

\footnotetext{
* Correspondence: mervecikili@yahoo.com; merveuytun@gmail.com

${ }^{1}$ Department of Child and Adolescent Psychiatry, Ankara University, Ankara,

Turkey

Full list of author information is available at the end of the article
}

leukamia, and also hemophilia [2-4]. It is showed that QoL in hemophilic was significantly poorer as compared with QoL of general population [5].

Additionally, caregivers of children with hemophilia report reduced health-related quality of life compared with caregivers of healthy children [6]. Managing the mothers' stress is important for themselves and as well as their children. Therefore, understanding of the contributor factors is important planning of psychological supports for the children and mothers of hemophilic children [7].

However especially in developing countries such as our country, Turkey, psychosocial support is not 
included in the general care and treatment for people with hemophilia and their parents mostly because of lack of financial resources, psychological supporting systems, and the emphasis on life-threatening bleeds and other medical complications [8].

This study aimed this to determine the psychiatric disorders and life quality in children with hemophilia and mother's anxiety, depression, and QoL scores and how the effect mother's psychological status on their children psychological problems in a sample of Turkish population.

\section{Methods}

\section{Subjects}

This study design is a case-control study. In our country, individuals under the age of 19 years are evaluated and treated in the departments of pediatrics and department of child and adolescent psychiatry according the definition of World Health Organization (WHO) [9].

All patients between the ages of $6-18$ years, who were followed up in our hospital, were included in this study. Some patients were excluded from the study because their parents could not fill the scales completely or could not complete the evaluation process $(n=7)$. As a result, a total of 20 children and adolescents with hemophilia A or B aged were included. All of the patients were boys. All of the children and adolescents who were enrolled in this study had been managed their treatment at the hemophilia centre of children hospital. Additionally, 20 male subjects with typical developing controls (TD) were recruited as the control group. TD group was selected randomly from pediatric outpatient clinics who do not have any chronic illness. Inclusion criteria for both hemophilia group and TDs were (i) age between 6 and 16 years, (ii) intelligence quotient (IQ) score higher than 70 , (iii) children living in their own family house and attending a normal primary school, (iv) no history of head injury with loss of consciousness, and (v) no neurological or other serious medical diseases.

\section{Instruments for assessment to children and adolescents}

Firstly, to determine psychiatric disorders of children and adolescents, a semi-structured interview: Kiddie-Schedule for Affective Disorders and Schizophrenia, present and life time version (K-SADS-PL) was applied to parents by a specialist of child psychiatry. It screens child and adolescent pschiatric disorders and symptoms. At the end of the interview, it is determined whether there is any disorder according to the diagnostic criteria [10].

Child Depression Inventory (CDI) was used. It includes 27 items and each item scores as 0,1 , or 2, and cutoff score of inventory for depression is 19 [11].

The Spielberger State-Trait Anxiety Inventory (STAI) consists of two questionnaires of 20 items each. The first questionnaire measures state anxiety (how one feels at the moment) and the second, trait anxiety (how one generally feels). Each item scores between 1 to 4, and the greater scores show the greater anxiety [12].

$K I N D L^{R}$ Questionnaire for Measuring Health-Related Quality of Life in children and adolescents was used. It could be completed both by children/adolescents and by their parents. Three versions of the KINDL ${ }^{\mathrm{R}}$ questionnaire are available as self-report measures for different age groups: Kiddy-KINDL ${ }^{\mathrm{R}}$ for children aged 4 to 7 , Kid- KINDL ${ }^{\mathrm{R}}$ for children aged 8 to 12 , and Kiddo$\mathrm{KINDL}^{\mathrm{R}}$ for adolescents aged 13 to 16 . The $\mathrm{KINDL}^{\mathrm{R}}$ questionnaire consists of 24 likert-scaled items associated with six dimensions: physical well-being, emotional well-being, self-esteem, family, friends, and everyday functioning (school or nursery school/kindergarten). All versions of the $\mathrm{KINDL}^{\mathrm{R}}$ contain an additional sub-scale entitled "Disease", whose items can be completed in case of prolonged illness or hospitalisation [13].

\section{Instruments for assessment to mothers}

Beck Depression Inventory (BDI) was used. It is a 21item self-report questionnaire in which each item consists of four statements indicating different levels of severity of a particular symptom experienced over the past week. Participants rate each item on 4-point scale ranging from 0 (absent) to 3 (severe), and total scores range from 0 to 63 [14].

Beck Anxiety Inventory (BAI) is a 21-item self-report measure that assesses level of anxiety and evaluates physical, emotional, and cognitive aspects of anxiety as well as fear of losing control. Total scores range from 0 to 63 and high scores indicate more severe anxiety symptoms [15].

The Burden Interview is a 22-item instrument to assess carers' burden associated to the patient's functional and behavioral disability and to the situation at home. The 22 items reflect respondent's areas of concern such as health, social and personal life, financial situation, emotional well-being, and interpersonal relationships. The greater the total score, the greater the burden [16].

The last scale for mothers was KINDL parent form. There are two parents' versions: Kiddy-KINDL ${ }^{\mathrm{R}}$ (4-7 years) and parents' version of the KINDL ${ }^{\mathrm{R}}$ for 8 to 16 years old children and teenagers [13].

\section{Procedure}

The interviews were performed during the usual visits of the patients to the hemophilia clinic. Firstly, the patients and their parents were interviewed together, and sociodemographic data was collected. Then, while children and adolescents were completing their scales, a child and adolescent psychiatry specialist applied to parents 
with the K-SADS-PL. After the KSADS-PL, the mothers completed their scales.

The Burden Interviews are especially related to caregiving for disabled persons so we did not give for control groups' parents different from the patient group.

This investigation was approved by the Ethical Committee of Erciyes University (2016\501). Written consent was obtained from parents, and verbal assent was requested from children and adolescents to participate.

\section{Statistical analysis}

In the two-way paired $t$ test, it was calculated to include 16 people that is enough to determine the differences between the scales at the level of 0.05 significance $(\alpha)$ with $80 \%$ power. In our study, it was planned to include 20 patients in the appropriate age range with follow-up in our department. Calculation was made with $G$ * Power 3.1.9.2. package program. We used Shapiro-Wilk test to analyze homogeneity of variables. Among-group differences on demographic variables were analyzed using independent samples $t$ tests. Mann-Whitney $U$ test were used for non-homogenous variables. Associations between categorical variables were examined using chisquare analysis. Spearman and Pearson correlation tests were used for assesment of correlation. Logistic and multiple regression analyzes were also used. Data analysis was performed using SPSS 24.0, and $p$ values $<0.05$ were considered statistically significant.

\section{Results}

Sociodemoghraphic variables of children and adolescents The sociodemographic and clinical characteristics of the patients are shown in Tables 1 and 2 .

Most of the patients suffered from hemarthrosis (80\%) and other types of bleeding (70\%). Fortunately, joint impairment (10\%) and chronic pain (10\%) were seen rarely in our patient sample, and viral infections including HBV, HCV, and HIV were negative in our all patients. Psychopathology was detected $30 \%$ of patients, and attention deficit and hyperactivity disorder (ADHD) is the most common diagnose in our patient sample (20\%).

Comparison of sociodemoghraphic variables between groups was shown in Table 3.

\section{Outcomes of children's scales}

The outcomes of scales of children and adolescents can be found in Fig. 1. It was found that patient group showed higher scores than controls on State-Trait Anxiety Inventory-Trait and State-Trait Anxiety InventoryTotal $(p<0.05)$. There was no significant differences between groups on KINDL-scales.

\section{The outcomes of scales of mothers}

Comparing patient group with control group, significant findings were shown in Fig. 2.

\section{The outcomes of correlation analyses}

Severity of illness has positive correlation only with prophylaxis $(r=0.54, p=0.01)$, and there was no correlation with any scale of children.

The correlations of the outcomes of scales of children and adolescents with outcomes of mothers were analyzed and summarized in Table 4.

Correlations of the outcomes of KINDL with other scales of children and adolescents were also analyzed (Table 5).

Logistic regresion analyzes were used to determine the effect of indepent variables on presence of psychopathology. First model was factors related to disease (severity, inhibitor, prophylaxis, hemophilia type) that could be explain $60 \%$ (nagelkerke $\mathrm{r}$ square) of the variance in the presence of psychopathology. The presence of pschopathology could not be predicted significantly in any of these factors alone. Second model was mothers' scales model (Beck depression, Beck Anxiety, and Burden Interview), and it could be explain 83\% (nagelkerke $\mathrm{r}$ square) of the variance in the presence of psychopathology $(p=0.001)$. However, the presence of pschopathology could not be predicted significantly in any of these factors alone.

The study analyzed the relationship between factors related to disease (severity, inhibitor, prophylaxis, hemophilia type) and mothers' scales (BDI, BAI and Burden Interview). In the regression analyzes, we found that Beck anxiety scores were predicted by severity of hemophilia $(p=0.05)$.

\section{Discussion}

The study results demonstrated higher anxiety scores and increased anxiety disorder diagnosis among children and adolescents with hemophilia. However, mothers' anxiety and depression scores are higher than the control group, and lower QoL scores of children also found in parents' KINDL forms. Mothers' depression and anxiety are associated with childrens' KINDL scores, CDI scores, and STAI scores. Presence of psychiatric disorder negatively correlated with KINDL-FF-subscales and positively correlated with BAI scores and BDI scores, and presence of psychiatric disorder was predicted by mothers' scales. Additionally, anxiety scores of mothers were predicted by severity of hemophilia.

Hemophilia does not predispose to any mental illness directly, but psychosocial factors affecting QoL include coping, social support, and overcome the difficulties caused by chronicity that may influence both as resources and stress factors the person with hemophilia 
Table 1 Sociodemoghraphic variables of children and adolescents with hemophilia

\begin{tabular}{|c|c|c|}
\hline \multirow[t]{3}{*}{ Age (years) $(n[\%])$} & $6-7$ & $3(15)$ \\
\hline & $8-12$ & $10(50)$ \\
\hline & $13-16$ & $7(35)$ \\
\hline \multirow[t]{2}{*}{ Place of residence } & Urban & $16(80)$ \\
\hline & Rural & $4(20)$ \\
\hline Mean of mother's age & $36.05 \pm 4.09$ & \\
\hline \multirow[t]{4}{*}{ Mother's educational status ( $n$ [\%]) } & No & $2(10)$ \\
\hline & Primary school & $11(55)$ \\
\hline & High school & $1(5)$ \\
\hline & University & $6(30)$ \\
\hline \multirow[t]{3}{*}{ Mother's profession ( $n$ [\%]) } & House wife & $14(70)$ \\
\hline & Public servant & $4(20)$ \\
\hline & Self-employed & $2(10)$ \\
\hline Mean of father's age (mean \pm SD) & $39.15 \pm 4.19$ & \\
\hline \multirow[t]{4}{*}{ Father's educational status ( $n[\%]$ ) } & Primary school & $8(40)$ \\
\hline & High school & $5(25)$ \\
\hline & University & $6(30)$ \\
\hline & Post university & $1(5)$ \\
\hline \multirow[t]{4}{*}{ Father's profession ( $n[\%])$} & Worker & $8(40)$ \\
\hline & Public Servant & $5(25)$ \\
\hline & Self-employed & $5(25)$ \\
\hline & Other & $2(10)$ \\
\hline Family type ( $n[\%])$ & Mother and father together & $20(100)$ \\
\hline \multirow[t]{2}{*}{ Kinship between parents ( $n[\%]$ ) } & No & $14(70)$ \\
\hline & Yes & $6(30)$ \\
\hline \multirow[t]{6}{*}{ Other hemophilic relatives ( $n[\%]$ ) } & None & $8(40)$ \\
\hline & Brother & $4(20)$ \\
\hline & Uncle & $4(20)$ \\
\hline & Grand father & $1(5)$ \\
\hline & Cousin & $1(5)$ \\
\hline & More than one relative & $2(10)$ \\
\hline Mothers' Burden Interview total score (mean \pm SD) & $38.05 \pm 17.81$ & \\
\hline
\end{tabular}

and his environment [17]. In the literature, several studies found that anxiety problems and depression were significantly seen much more frequently in hemophiliac patients compared with the control group $[18,19]$. However, in a study, there was no differences between the hemophilic subjects and healthy controls in depression scores, and they concluded that although a higher distress and psychological problems could occur in the patients, hemophilic patients could show a good adjustment to this disease, like many other chronic diseases, and it can be accepted as a "life condition" that they can live with [20].

Significant differences between groups on all of STAI scores and although depressive sypmtoms were higher in the hemophilia group that were found, it did not reach statistical significance. Being in a developing country makes our patients at higher risk for complications such as hemarthrosis, muscle hematomas, and other bleedings and was showed frequently in our study. Also, this result might be attributed to small sample, or anxiety might be more a consistent psychological problem associated with hemophilia.

As in previously published studies [21-23], patients presented a good QoL in this study, and no significantly difference between groups on KINDL scores were found. However, we showed that QoL scores of patients were higher than the control group in school, self-esteem, and family subscales. Failure to detect such QOL scores in 
Table 2 Clinical variables of children and adolescents with hemophilia

\begin{tabular}{|c|c|c|}
\hline \multirow[t]{2}{*}{ Haemophilia type ( $n$ [\%]) } & Hemophilia A & $16(80)$ \\
\hline & Hemophilia B & $4(20)$ \\
\hline \multirow[t]{3}{*}{ Severity (factor level) (n [\%]) } & Mild & $4(20)$ \\
\hline & Moderate & $6(30)$ \\
\hline & Severe & $10(50)$ \\
\hline Age at diagnosis (months) mean \pm SD & $10.18 \pm 12.24$ & \\
\hline \multirow[t]{2}{*}{ Inhibitor (ever) } & No & $18(90)$ \\
\hline & Yes & $2(10)$ \\
\hline \multirow[t]{3}{*}{ Prophylaxis ( $\boldsymbol{n}[\%]$ ) } & No & $3(15)$ \\
\hline & Transient & $8(40)$ \\
\hline & Constant & $9(45)$ \\
\hline \multirow[t]{4}{*}{ Haemarthrosis (ever) ( $n$ [\%]) } & No & $4(20)$ \\
\hline & $1-3$ & $8(40)$ \\
\hline & $4-5$ & $3(15)$ \\
\hline & More than 5 & $5(25)$ \\
\hline \multirow[t]{2}{*}{ Muscle hematomas (ever) ( $n$ [\%]) } & No & $11(55)$ \\
\hline & Yes & $9(45)$ \\
\hline \multirow[t]{2}{*}{ Other bleeding (ever) ( $n$ [\%]) } & No & $6(30)$ \\
\hline & Yes & $14(70)$ \\
\hline \multirow[t]{2}{*}{ Joint impairment (ever) ( $n$ [\%]) } & No & $18(90)$ \\
\hline & Yes & $2(10)$ \\
\hline \multirow[t]{2}{*}{ Chronic pain (ever) (n [\%]) } & No & $18(90)$ \\
\hline & Yes & $2(10)$ \\
\hline Hepatitis B/C and HIV ( $n$ [\%]) & Negative & $20(100)$ \\
\hline \multirow[t]{2}{*}{ Psychopathology ( $[$ [\%]) } & No & $14(70)$ \\
\hline & Yes & $6(30)$ \\
\hline \multirow[t]{5}{*}{ Psychiatric diagnosis ( $n$ [\%]) } & ADHD & $2(10)$ \\
\hline & ADHD+ODD & $1(5)$ \\
\hline & ADHD+ODD+GAD & $1(5)$ \\
\hline & Depression & $1(5)$ \\
\hline & GAD+adjustment disorder & 1 (5) \\
\hline
\end{tabular}

$A D H D$ attention deficit and hyperactivity disorder, $O D D$ oppositional deficit disorder, $G A D$ generalized anxiety disorder, $S D$ standart deviation

our study might be related to the several different factors such as personal characteristics (self-esteem, selfconcept, and self-perception, etc.), ethnicity, and parenting styles. Because of higher scores in self-esteem subscale in the patient group, it could be a reason for higher KINDL scores. Although it was not previously assessed in relationship with hemophilia, previous studies suggested that Arab society tends to perceive illness and disability as God's will, which may promote acceptance and adjustment, and it is similar with religious context of our country. Also, it is known that overprotected pattern is usual especially at the beginning of the illness; therefore, higher KINDL family scores in hemophilia group than the control group might be related to this parenting style $[24,25]$.
Literature reveals that boys with hemophilia face some challenges in their peer interactions, such as awareness of being different from their same-sex peers, make efforts to conceal differences from these peers, and attempt to connect with peers in various ways [26]. All of this social traits may be caused to disfunction in social subscale. Although the children did not show any difference in KINDL subscales, mothers reported lower QoL scores especially in family and friends' subscales.

Parents play a significant role in the care of a child with hemophilia and take a large responsibility for management of hemophilia at home [27]. Most of the studies identified that parents whose child with hemophilia have more anxiety, depression, physical problems, cognitive problems and more parental attitude problems, and 
Table 3 Comparison of sociodemoghraphic variables between groups

\begin{tabular}{|c|c|c|c|}
\hline Group & Patient group, mean \pm SD $(n[\%])$ & TD group, mean \pm SD $(n[\%])$ & Group differences \\
\hline Mean of age & $10.95 \pm 2.94$ & $10.55 \pm 2.45$ & $p=0.69$ \\
\hline \multicolumn{4}{|l|}{ Gender } \\
\hline Male ( $n[\%])$ & $20(100 \%)$ & $20(100 \%)$ & $p=1$ \\
\hline Education class & $4.95 \pm 2.94$ & $5.05 \pm 3.74$ & $p=0.92$ \\
\hline Mean of mother's age & $36.5 \pm 4.09$ & $38.6 \pm 5.75$ & $p=0.11$ \\
\hline \multicolumn{4}{|l|}{ Mother's educational status ( $n[\%]$ ) } \\
\hline No & $2(10)$ & - & $p=0.4$ \\
\hline Primary school & $6(30)$ & $3(15)$ & \\
\hline Secondary school & $5(25)$ & $6(30)$ & \\
\hline High school & $1(5)$ & $2(10)$ & \\
\hline University & $6(30)$ & $9(45)$ & \\
\hline \multicolumn{4}{|l|}{ Mother's profession ( $[\%]$ ) } \\
\hline House wife & $14(70)$ & $11(55)$ & $p=0.54$ \\
\hline Public servant & $4(20)$ & $6(30)$ & \\
\hline Self-employed & $2(10)$ & $2(10)$ & \\
\hline Worker & - & $1(5)$ & \\
\hline Median of father's age & $39.15 \pm 4.19$ & $40.9 \pm 4.75$ & $p=0.22$ \\
\hline \multicolumn{4}{|l|}{ Father's educational status ( $n[\%]$ ) } \\
\hline Primary school & $5(25)$ & $1(5)$ & $p=0.21$ \\
\hline Secondary school & $3(15)$ & $3(15)$ & \\
\hline High school & $5(25)$ & $4(20)$ & \\
\hline University & $7(35)$ & $12(60)$ & \\
\hline \multicolumn{4}{|l|}{ Father's profession ( $[\%]$ ) } \\
\hline Worker & $8(40)$ & $4(20)$ & $p=0.04^{*}$ \\
\hline Public servant & $5(25)$ & $12(60)$ & \\
\hline Self-employed & $5(25)$ & $3(15)$ & \\
\hline Other & $2(10)$ & $1(5)$ & \\
\hline \multicolumn{4}{|l|}{ Family type ( $n[\%])$} \\
\hline Mother and Father together & $20(100)$ & $19(95)$ & $p=0.31$ \\
\hline Divorced- living with a single parent & - & 1 (5) & \\
\hline
\end{tabular}

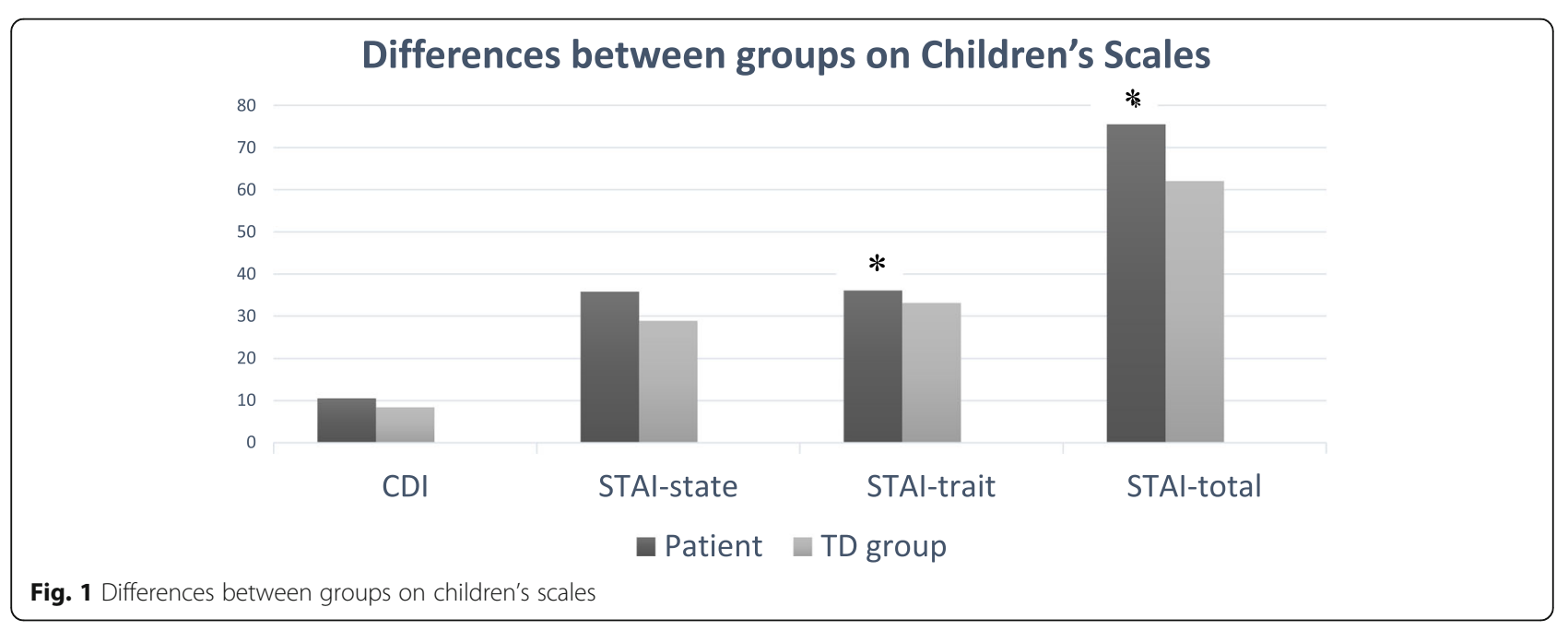




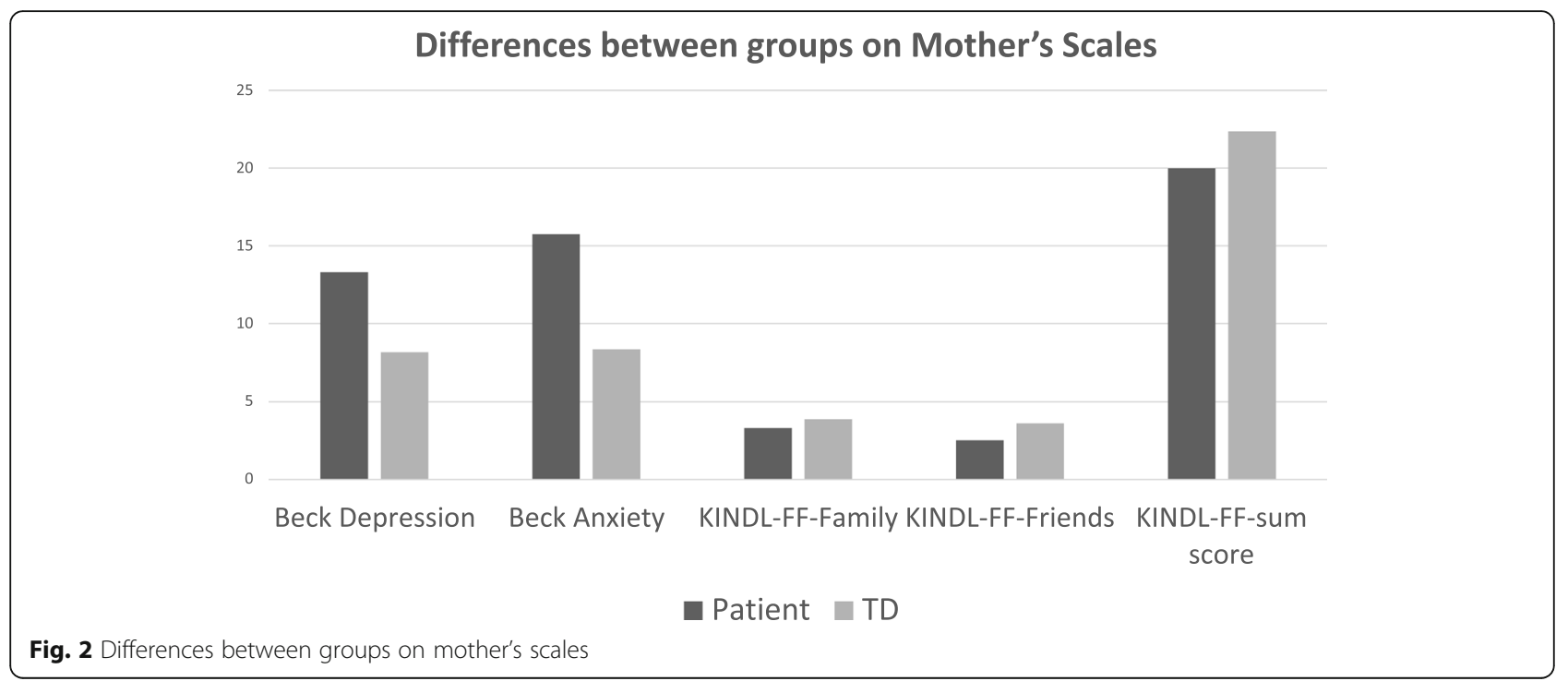

lower health-related quality of life (HRQOL) than parents of healthy children [18, 27, 28]. In our study, consistent with the literature, we found that in parents of hemophilic children show higher depression and anxiety scores than the control group, and psychological status of children could be predicted by mothers' psychological status. Additionally, anxiety scores of mothers were predicted by severity of hemophilia that is similar with other studies which showed that the parents of the boys with hemophilia are deeply affected by their child's condition $[27,29,30]$.

"Burden" has become a more popular term in recent years and in studies, parents of children with chronic illness report social, financial, and emotional burden [31]. The results showed positive correlation between burden scores and mothers' anxiety, depression scores, and childrens' anxiety scores. We concluded that mothers' anxiety and depression could increase burden scores, and this could affect the anxiety levels of children indirectly.

\section{Study limitations}

There are several limitiations in the study. First, the small size of the sample might limit the generalization of the results on Turkish children or in children with

Table 4 Correlation of the outcomes of scales of children and adolescents with outcomes of mothers

\begin{tabular}{|c|c|c|c|c|c|c|c|c|}
\hline & \multicolumn{2}{|c|}{ Beck Anxiety Scores } & \multicolumn{2}{|c|}{ Beck Depression Scores } & \multicolumn{2}{|c|}{$\begin{array}{l}\text { KINDL-FF } \\
\text { Sum Score } \\
\end{array}$} & \multicolumn{2}{|c|}{ Burden Interview Scores } \\
\hline & $r$ & $p$ & $r$ & $p$ & $r$ & $p$ & $r$ & $p$ \\
\hline Age & 0.14 & 0.37 & 0.13 & 0.41 & -0.48 & 0.001 & -0.06 & 0.8 \\
\hline Presence of psychiatric disorder & 0.59 & 0.005 & 0.69 & $<0.001$ & -0.58 & 0.005 & 0.34 & 0.13 \\
\hline CDI & 0.46 & 0.002 & 0.51 & 0.001 & -0.46 & 0.003 & 0.44 & 0.04 \\
\hline STAI-State & 0.34 & 0.02 & 0.58 & $<0.001$ & -0.33 & 0.03 & 0.46 & 0.04 \\
\hline STAI-Trait & 0.32 & 0.04 & 0.490 & 0.001 & -0.37 & 0.01 & 0.39 & 0.08 \\
\hline STAI-total scores & 0.37 & 0.01 & 0.59 & $<0.001$ & -0.39 & 0.01 & 0.48 & 0.03 \\
\hline \multicolumn{9}{|l|}{ KINDL } \\
\hline KINDL-Physical Well-being & -0.40 & 0.009 & -0.42 & 0.006 & -0.006 & 0.96 & -0.25 & 0.27 \\
\hline KINDL-Emotional Well-being & -0.43 & 0.005 & -0.46 & 0.003 & 0.6 & $<0.001$ & -0.32 & 0.16 \\
\hline KINDL-Self Esteem & -0.26 & 0.09 & -0.31 & 0.04 & 0.69 & $<0.001$ & -0.11 & 0.63 \\
\hline KINDL-Family & -0.29 & 0.06 & -0.28 & 0.07 & 0.46 & 0.002 & -0.26 & 0.26 \\
\hline KINDL-Friends & -0.21 & 0.17 & -0.28 & 0.07 & 0.37 & 0.01 & -0.11 & 0.63 \\
\hline KINDL-School & 0.02 & 0.87 & -0.26 & 0.1 & 0.32 & 0.03 & -0.10 & 0.66 \\
\hline KINDL-Sum score & -0.41 & 0.009 & -0.52 & 0.001 & 0.78 & $<0.001$ & -0.30 & 0.19 \\
\hline
\end{tabular}

CDI Child Depression Inventory, STAI The Spielberger State-Trait Anxiety Inventory, KINDL-FF KINDL - Family Form Significance indicated in bold 
Table 5 Correlation of the outcomes of KINDL with other scales of children and adolescents

\begin{tabular}{|c|c|c|c|c|c|c|c|c|c|c|}
\hline & \multicolumn{2}{|c|}{$\begin{array}{l}\text { Beck Anxiety } \\
\text { Scores }\end{array}$} & \multicolumn{2}{|c|}{$\begin{array}{l}\text { Beck Depression } \\
\text { Scores }\end{array}$} & \multicolumn{2}{|c|}{$\begin{array}{l}\text { KINDL-FF } \\
\text { Sum Score }\end{array}$} & \multicolumn{2}{|c|}{$\begin{array}{l}\text { The Level of Expressed } \\
\text { Emotion }\end{array}$} & \multicolumn{2}{|c|}{$\begin{array}{l}\text { Burden Interview } \\
\text { Scores }\end{array}$} \\
\hline & $r$ & $p$ & $r$ & $p$ & $r$ & $p$ & $r$ & $p$ & $r$ & $p$ \\
\hline Age & 0.14 & 0.37 & 0.13 & 0.41 & -0.48 & 0.001 & 0.18 & 0.44 & -0.06 & 0.8 \\
\hline Presence of psychiatric disorder & 0.59 & 0.005 & 0.69 & $<0.001$ & -0.58 & 0.005 & 0.45 & 0.04 & 0.34 & 0.13 \\
\hline CDI & 0.46 & 0.002 & 0.51 & 0.001 & -0.46 & 0.003 & 0.39 & 0.08 & 0.44 & 0.04 \\
\hline STAI-State & 0.34 & 0.02 & 0.58 & $<0.001$ & -0.33 & 0.03 & 0.15 & 0.5 & 0.46 & 0.04 \\
\hline STAI-Trait & 0.32 & 0.04 & 0.490 & 0.001 & -0.37 & 0.01 & 0.67 & 0.001 & 0.39 & 0.08 \\
\hline STAI-total scores & 0.37 & 0.01 & 0.59 & $<0.001$ & -0.39 & 0.01 & 0.45 & 0.04 & 0.48 & 0.03 \\
\hline \multicolumn{11}{|l|}{ KINDL } \\
\hline KINDL-Physical Well-being & -0.40 & 0.009 & -0.42 & 0.006 & -0.006 & 0.96 & -0.26 & 0.25 & -0.25 & 0.27 \\
\hline KINDL-Emotional Well-being & -0.43 & 0.005 & -0.46 & 0.003 & 0.6 & $<0.001$ & -0.45 & 0.04 & -0.32 & 0.16 \\
\hline KINDL-Self Esteem & -0.26 & 0.09 & -0.31 & 0.04 & 0.69 & $<0.001$ & -0.44 & 0.04 & -0.11 & 0.63 \\
\hline KINDL-Family & -0.29 & 0.06 & -0.28 & 0.07 & 0.46 & 0.002 & -0.17 & 0.43 & -0.26 & 0.26 \\
\hline KINDL-Friends & -0.21 & 0.17 & -0.28 & 0.07 & 0.37 & 0.01 & -0.13 & 0.59 & -0.11 & 0.63 \\
\hline KINDL- chool & 0.02 & 0.87 & -0.26 & 0.1 & 0.32 & 0.03 & -0.21 & 0.35 & -0.10 & 0.66 \\
\hline KINDL-Sum score & -0.41 & 0.009 & -0.52 & 0.001 & 0.78 & $<0.001$ & -0.42 & 0.06 & -0.30 & 0.19 \\
\hline
\end{tabular}

CDI Child Depression Inventory, STAI The Spielberger State-Trait Anxiety Inventory, KINDL-FF KINDL - Family Form

Significance indicated in bold

hemophilia in general, and it remains as a preliminary study. This small number did not allow for the determination of differences in QoL. Second, the study data depended entirely on the patients' subjective assessment of their own quality of life. Furthermore, other confounding factors, such as parenting styles, marriage relationship, and child's temperament were not taken into account.

\section{Conclusion}

In conclusion, results demonstrate there are high proportions of the psychiatric disorders and symptoms in the children and adolescents with hemophilia and their parents. Most signicantly, the study emphasizes that psychiatric factors should not be ignored in the treatment and follow-up of children and adolescents with hemophilia. Additionally, health care professionals who were working with such patients must be aware of the warning signs of deeper psychiatric problems, and psychiatric consultation needs to be included in the management of these children. It may be recommended to prepare a range of intervention programs to be applied at hospital for the children with chronic diseases and especially for those with hemophilia. In addition, interventions should include social interventions such as specific peer relationships. These programs can help parents to manage and cope with their children's chronic conditions more efficiently.

We hope that these findings encourage more research on psychosocial functioning of children and their parents in a larger sample, which is a limitation of this study, and psyhological support programs for hemophilia will become available in our country.

\section{Abbreviations}

BDI: Beck Depression Inventory; BAI: Beck Anxiety Inventory; K-SADSPL: Kiddie-Schedule for Affective Disorders and Schizophrenia, present and life time version; QoL: Quality of life; WHO: World Health Organization; TD: Typical developing controls; IQ: Intelligence quotient; CDI: Child Depression Inventory; STAI: The Spielberger State-Trait Anxiety Inventory; HRQOL: Health-related quality of life

\section{Acknowledgements}

We thank the Erciyes Thalessemia and Hemophilia Association. Findings of this study was presented as a poster in the 12th Annual Congress of the European Association for Haemophilia and Allied Disorders 2019, 6-8 February 2019, Prague, Czech Republic.

\section{Authors' contributions}

SU, YAT, MK, and FTM assessed the patients with hemophilia. MCU, FHC, RY, and ZB applied psychological scales and made psychiatric assesment. MCU writed the article, and the others revised it. All authors have read and approved the manuscript.

Funding

There is no funding.

\section{Availability of data and materials}

The datasets used and/or analyzed during the current study are available from the corresponding author on reasonable request.

\section{Ethics approval and consent to participate}

Written consent was obtained from parents, and verbal assent was requested from children and adolescents to participate. This investigation was approved by the Ethical Committee of Erciyes University, Turkey with 2016\501 number.

Consent for publication

Not Applicable. 


\section{Competing interests}

The authors declare that they have no competing interests

\section{Author details}

'Department of Child and Adolescent Psychiatry, Ankara University, Ankara, Turkey. ${ }^{2}$ Department of Child and Adolescent Psychiatry, Selcuk University, Konya, Turkey. ${ }^{3}$ Department of Child and Adolescent Psychiatry, Kayseri Training and Research Hospital, Kayseri, Turkey. ${ }^{4}$ Department of Pediatrics, Kayseri Training and Research Hospital, Kayseri, Turkey. ${ }^{5}$ Department of Pediatric Hematology, Kayseri Training and Research Hospital, Kayseri, Turkey.

Received: 14 November 2019 Accepted: 11 June 2020

Published online: 20 July 2020

\section{References}

1. Srivastava A, Brewer AK, Mauser-Bunschoten EP, Key NS, Kitchen S, Llinas A et al (2013) Guidelines for the management of hemophilia. Haemophilia 19(1):e1-e47. https://doi.org/10.1111/j.1365-2516.2012.02909.x

2. Fardell JE, Vetsch J, Trahair T, Mateos M, Grootenhuis M, Touyz L et al (2017) Health-related quality of life of children on treatment for acute lymphoblastic leukemia: a systematic review. Pediatr Blood Cancer 64(9): e26489

3. Miadich SA, Everhart RS, Borschuk AP, Winter MA, Fiese BH (2015) Quality of life in children with asthma: a developmental perspective. J Pediatr Psychol 40(7):672-679

4. Von Mackensen S, Harrington C, Tuddenham E, Littley A, Will A, Fareh M et al (2016) The impact of sport on health status, psychological well-being and physical performance of adults with haemophilia. Haemophilia 22(4): $521-530$

5. Klamroth R, Pollmann H, Hermans C, Faradji A, Yarlas AS, Epstein JD et al (2011) The relative burden of haemophilia a and the impact of target joint development on health-related quality of life: results from the ADVATE post-authorization safety surveillance (PASS) study. Haemophilia 17(3):412421. https://doi.org/10.1111/j.1365-2516.2010.02435.x

6. Lindvall K, von Mackensen S, Elmstahl S, Khair K, Stain AM, Ljung R et al (2014) Increased burden on caregivers of having a child with haemophilia complicated by inhibitors. Pediatr Blood Cancer 61(4):706-711. https://doi. org/10.1002/pbc.24856

7. Kang H, Kim W, Jeong Y, Kim S, Yoo K (2012) Effect of a self-help program for mothers of hemophilic children in Korea. Haemophilia 18(6):892-897

8. Spilsbury M (2004) Models for psychosocial services in the developed and developing world. Haemophilia 10(Suppl 4):25-29. https://doi.org/10.1111/j. 1365-2516.2004.01002.x

9. World Health Organization, (W. H. O.) (2013). Definition of key terms. https:// www.who.int/hiv/pub/guidelines/arv2013/intro/keyterms/en/. Accessed 22 Jan 2019.

10. Gökler B, Ünal F, Pehlivantürk B, Kültür EÇ, Akdemir D, Taner Y (2004) Reliability and validity of schedule for affective disorders and schizophrenia for school age children-present and lifetime version-Turkish version (KSADS-PL-T). Turk J Child Adolesc Mental Health 11(3):109-116

11. Kovacs M (1992) Children's depression inventory. Multi-Health Systems North Tonawanda, NY

12. Spielberger CD (2010) State-Trait anxiety inventory. Wiley Online Library

13. Ravens-Sieberer U, Erhart M, Wille N, Wetzel R, Nickel J, Bullinger M (2006) Generic health-related quality-of-life assessment in children and adolescents. Pharmacoeconomics 24(12):1199-1220

14. Beck, A., \& Steer, R. (1987). Beck Depression Inventory. The Psychological Corporation Harcourt Brace Jovanovich. Inc., Pages.

15. Beck AT, Epstein N, Brown G, Steer RA (1988) An inventory for measuring clinical anxiety: psychometric properties. J Consult Clin Psychol 56(6):893

16. Zarit SH, Reever KE, Bach-Peterson J (1980) Relatives of the impaired elderly: correlates of feelings of burden. Gerontologist 20(6):649-655

17. Garcia-Dasi M, Torres-Ortuno A, Cid-Sabatel R, Barbero J (2016) Practical aspects of psychological support to the patient with haemophilia from diagnosis in infancy through childhood and adolescence. Haemophilia 22(5):e349-e358. https://doi.org/10.1111/hae.13018

18. Abali O, Zulfikar OB, Karakoc Demirkaya S, Ayaydin H, Kircelli F, Duman M (2014) An examination of the symptoms of anxiety and parental attitude in children with hemophilia. Turk J Med Sci 44(6):1087-1090 https://www.ncbi. nlm.nih.gov/pubmed/25552165
19. Hassan TH, Badr MA, Fattah NR, Badawy SM (2011) Assessment of musculoskeletal function and mood in haemophilia a adolescents: a crosssectional study. Haemophilia 17(4):683-688. https://doi.org/10.1111/j.13652516.2010.02475.x

20. Canclini M, Saviolo-Negrin N, Zanon E, Bertoletti R, Girolami A, Pagnan A (2003) Psychological aspects and coping in haemophilic patients: a casecontrol study. Haemophilia 9(5):619-624

21. Garcia-Dasi M, Aznar JA, Jimenez-Yuste V, Altisent C, Bonanad S, Mingot E et al (2015) Adherence to prophylaxis and quality of life in children and adolescents with severe haemophilia a. Haemophilia 21(4):458-464. https:// doi.org/10.1111/hae.12618

22. Royal S, Schramm W, Berntorp E, Giangrande P, Gringeri A, Ludlam C et al (2002) Quality-of-life differences between prophylactic and on-demand factor replacement therapy in European haemophilia patients. Haemophilia 8(1):44-50 http://www.ncbi.nlm.nih.gov/pubmed/11886464

23. Mackensen SVON (2007) Quality of life and sports activities in patients with haemophilia. Haemophilia 13(Suppl 2):38-43. https://doi.org/10.1111/j.13652516.2007.01505.x

24. Folkman S (2013) Stress: appraisal and coping. Encyclopedia of behavioral medicine. Springer, pp 1913-1915

25. Yamey G, Greenwood R (2004) Religious views of the 'medical'rehabilitation model: a pilot qualitative study. Disabil Rehabil 26(8):455-462

26. Williams KA, Chapman MV (2011) Social challenges for children with hemophilia: child and parent perspectives. Soc Work Health Care 50(3):199214. https://doi.org/10.1080/00981389.2010.527790

27. DeKoven M, Karkare S, Kelley LA, Cooper DL, Pham H, Powers J et al (2014) Understanding the experience of caring for children with haemophilia: cross-sectional study of caregivers in the United States. Haemophilia 20(4): 541-549. https://doi.org/10.1111/hae.12379

28. Bullinger M, Globe D, Wasserman J, Young NL, von Mackensen S (2009) Challenges of patient-reported outcome assessment in hemophilia care-a state of the art review. Value Health 12(5):808-820. https://doi.org/10.1111/j. 1524-4733.2009.00523x

29. Beeton K, Neal D, Watson T, Lee CA (2007) Parents of children with haemophilia--a transforming experience. Haemophilia 13(5):570-579. https:// doi.org/10.1111/j.1365-2516.2007.01494.x

30. Wiedebusch S, Pollmann H, Siegmund B, Muthny FA (2008) Quality of life, psychosocial strains and coping in parents of children with haemophilia. Haemophilia 14(5):1014-1022. https://doi.org/10.1111/j.1365-2516.2008. 01803.x

31. Khanna AK, Prabhakaran A, Patel P, Ganjiwale JD, Nimbalkar SM (2015) Social, psychological and financial burden on caregivers of children with chronic illness: a cross-sectional study. Indian J Pediatrics 82(11):1006-1011

\section{Publisher's Note}

Springer Nature remains neutral with regard to jurisdictional claims in published maps and institutional affiliations.

\section{Submit your manuscript to a SpringerOpen ${ }^{\bullet}$ journal and benefit from:}

- Convenient online submission

- Rigorous peer review

- Open access: articles freely available online

- High visibility within the field

- Retaining the copyright to your article

Submit your next manuscript at $>$ springeropen.com 